\title{
Losses and Economic Capital under Climate Change Dependence in Taiwan: The Case of Crop
}

\author{
Li-Hua Lai \\ Tung-Cheng Chang \\ Kai-Wen Wong \\ Ching-Hsuan Dai
}

\begin{abstract}
This research will first examine the impact of climate change, tail loss and economic capital on major crops losses due to single-peril in crop insurance program based on panel data using copula-simulation method for 10 major crops over the 1971-2012. The purpose of this research will build the copula of temperature, precipitation and sunshine duration are copula to be the major climate variables and to assess the tail value at risk (TVaR) loss and economic capital models under climate changes copula estimated. The findings will be important in providing useful knowledge to future help examining risk measures that measure TVaR loss that can be used for determining provisions and capital requirements in order to avoid insolvency on government agricultural budgeting or insurer's coverage and to discovering effective regulations of crop insurance design and to enhance the efficiency of agricultural markets in future.
\end{abstract}

Keywords-climate change copulaed, COPULA-AR-GARCH loss models, economic capital

Li-Hua Lai (Prof.) (Corresponding author)

Department of Risk Management and Insurance/National Kaohsiung First University of Science and Technology

Taiwan

Tung-Cheng Chang (Ph.D. candidate)

Department of Risk Management and Insurance/National Kaohsiung First University of Science and Technology

Taiwan

Kai-Wen Wong (M.B.A. student)

Department of Risk Management and Insurance/National Kaohsiung First University of Science and Technology

Taiwan

Ching-Hsuan Dai (Master's graduate)

Department of Risk Management and Insurance/National Kaohsiung First

University of Science and Technology

Taiwan

\section{Introduction}

Climate change has both biophysical as well as socioeconomic effects that influence agricultural production (Antonio and Beirlant, 2007; Kalisch et al., 2011). The crop production is largely concentrated in Asia (Luo et al., 1998; Chang, 2002; Chatrath et al., 2002; Yun, 2003). In all the phenomena of climate change, the effect can result in losses of the type that are the most catastrophic, not only their fierceness but also frequency of occurrence. Climate change has always been a source of single-peril risk or combinedperil risk for many crops and relieved facilities (Kalisch et al. 2011). The occurrence of weather episodes such as extreme perils characterized by maximum or minimum temperature, sequences of precipitation days, and sunshine duration during occurrence of typhoon, flood, frost damage, drought, hailstone, storm damage, front, tornado and disease may significantly affect crop yield loss.

Climate change has always been a source of single-peril risk or combined-peril risk for many crops and relieved facilities (Kalisch et al., 2011). Single-risk insurances are the main lines available which is well develop with a long history in EU, such as UK and Germany hail insurance. Some pretention of crop insurance become controversial or even unavailable such as adverse selection, multiple-peril coverage, yield loss-based pricing, loss ratio-based rating, participation in US. (Skees and Reed, 1986; Goodwin, 1993, 1994; Barry and Skees, 1994; Babcock et al., 2004; Glauber 2004; Carriquiry et al., 2008; Rejesus, et al., 2010; Woodard et al., 2011). However, experience with agricultural yield insurance applications has shown that the aggregation of crop yields causes errors in the risk assessment for farmlevel analysis (Rudstrom et al., 2002; Cooper et al., 2009).

Risk measures of insurance price, $\mathrm{VaR}$ and $\mathrm{TVaR}$ are meant to provide a degree of magnitude of the severity of a potential loss in a coverage portfolio and are therefore meaningful amounts to hold to cover for the risk exposure in agricultural loss. Premium principles are clear examples of risk measures, and these have been extensively explored (Goovaerts et al., 1984; Kaas et al., 2001). In some countries is less develop in the private crop, but there is public crop compensation scheme provided to compensate yield losses after natural disasters. Combined-risk is two or more of perils in an insurance coverage in US (as multiple-peril crop insurance, MPCI) and Sweden. Note that the combined-risk differs from that of MPCI which the yield losses by plagues and diseases and damages are calculated simply as the difference between guaranteed and actual in US. A widely recognized feature of crop yield loss data are high levels of both temperature and precipitation dependence in region.

According to statistics of Taiwan's Agriculture Yearbook, significant financial losses in agricultural sector in Taiwan are commonly caused from various natural events (Chang, 2002; Chen and Chang, 2005; Chang et al., 2012; Lai, 2015) such as typhoons, floods, droughts, insects, earthquakes, hails, and so on. Changes in temperature and precipitation truly have combined to render the remotest corners of the region accessible (Chang, 2002; Chen and Chang, 2005; Chang et al., 2012) in Taiwan. Characteristics of disasters in Taiwan are similar to those of global disasters, such as the annual mean temperature in Taiwan increased by $1.1 \sim 1.6^{\circ} \mathrm{C} /$ century. Regions where at least $75 \%$ of all models agree on the precipitation response direction are highlighted in orange to show decreasing precipitation, but the number of torrential rain days ( daily rainfall $\geqslant 200$ $\mathrm{mm}$ ) has increased. These result carries the possibility of crop yield loss, not only for the individual framer, but also 
Proc. of the Seventh International Conference On Advances in Economics, Management and Social Study - EMS 2017. Copyright (C) Institute of Research Engineers and Doctors. All rights reserved.

ISBN: 978-1-63248-128-3 doi: 10.15224/ 978-1-63248-128-3-39

for its customers. Since 1971-2014, total losses due to natural peril have been over US\$ 7428 million in crops (including facilities). An agricultural exposure unit is, roughly, crop exposed to the possibility of loss, for example, fruit $(53 \%)$, vegetable $(14 \%)$, rice $(13 \%)$, special crops $(7 \%)$, mixed grain $(6 \%)$ cut flowers (1.76), and facility $(0.69 \%)$. Major natural perils include single-peril event such as typhoons (73\%), floods (16\%), frost damage (4\%), drought $(2 \%)$ and/or combined-perils in crops damaged (Lai, 2010, 2015; Lai and $\mathrm{Wu}, 2013)$. Here that depending on the temperature, precipitation days, sunshine duration and prospective crops-specific-peril damages may vary considerably

This paper follow part of the risk-peril event on the Copula-AR-GARCH Loss model (Lai, 2017), and display on the copula of temperature, precipitation and sunshine duration are copula to be the major climate variables and to assess the tail value at risk TVaR based economic capital (Calem, P.S. and LaCour-Little, 2001, 2004; Lai 2017), which can also give us the level of unexpected loss in crop losses under climate changes copula estimated. The findings will be important in providing useful knowledge to future help examining risk measures that measure TVaR loss that can be used for determining provisions and capital requirements in order to avoid insolvency on government agricultural budgeting or insurer's coverage and to discovering effective regulations of crop insurance design and to enhance the efficiency of agricultural markets in future.

\section{Model and methodology}

In collective risk model, the number of losses and are a random variable and is associated with the frequency of crop or facility loss (c) due to the single-peril $(\psi=x 1)$ or combined-peril $(\psi=x 12)$ in county-level given time period $(\mathrm{t})$. The individual losses $l_{1}, l_{2}, \ldots$ are also random variables and are said to measure the severity of crop or facility losses. In an insurance contract, it will cover the crop-facility loss due to combined-peril y. In risk models, the random sum (Bowers et al., 1997; Boland, 2007) represents the aggregate losses generated by the portfolio for the period under studies (Lai, 2015, 2017) and AR(1)$\operatorname{GJR}(1,1)$ - GARCH(1,1) loss model with climate changes copula estimated (Lai, 2016, 2017). This paper choose to work with the tail value at risk of $\mathrm{L}_{\Omega}$ under extreme clime typhoon-flood perils in major insurance coverage at level $\eta$, for $\eta \in(0,1)$. Its definition is

$$
\operatorname{TVaR}_{\kappa}\left[\mathrm{L}_{\Omega}\right]=\frac{1}{1-\eta} \int_{\eta}^{1} \operatorname{VaR}\left[\mathrm{L}_{\Omega}\right] d \kappa
$$

or

$$
\operatorname{TVaR}_{k}\left[\mathrm{~L}_{\Omega}\right]=\mathrm{E}\left[\mathrm{L}_{\Omega} \mid \mathrm{L}_{\Omega}>\operatorname{VaR} R_{\eta}\left[\mathrm{L}_{\eta}\right]\right]=\operatorname{CTE}\left[\mathrm{L}_{\eta}\right]
$$

In general, when $L$ is continuous, $\operatorname{Pr}\left(\mathrm{L}_{\Omega} \leq \operatorname{VaR}_{\eta}\left[\mathrm{L}_{\Omega}\right]\right)=\eta$ which implies that is exactly the conditional tail expectation (CTE) meaning in specifiedperil coverage. Let the aggregate budget or insurance premium equal to aggregate premium for this study, for a holding level $\phi$, the TVaR-based economic capital is thus defined as

$$
\mathrm{EC}\left[\mathrm{S}_{\Omega}, \phi\right]=\mathrm{TVaR}\left[\mathrm{S}_{\Omega}, \phi\right]-\mathrm{E}\left[\mathrm{S}_{\Omega}\right]
$$

In general, setting the amount of additional capital equal to $\mathrm{TVaR}[\mathrm{S}, \phi]$-premium, we can define bad time which the aggregate losses of crop insurance excess the threshold, but do not use up all available capital. This value will be used to determine the risk transfer arrangement to be selected for catastrophe cover. However, the TVaR-based economic capital which can also give us the level of unexpected loss in crop losses. Finally, this study will examine risk measures that measure upper tails of distribution functions that can be used for determining provisions and capital requirements in order to avoid insolvency on government agricultural budgeting or insurer's coverage.:.

\section{Results of the TVaR and economic capital under climate change dependence}

\section{A. The data}

This paper investigate the crop damage caused by typhoons and floods effect of the conditional copulaGARCH methodology for the period between January, 1971 and December, 2012. This paper focuses on 8 crop types (including 52 sub-items) in Taiwan and is available at http://www.coa.gov.tw. The descriptive statistics chosen include: Mean, Median, Maximum, Minimum, Standard Deviation, Skewness, Kurtosis, Jarque-Bera, Sum and Sum Square Deviation in 1971-2012. For one month, the typhoons and floods loss ranged from 0 to 0.5631 billion and from 0 to 0.1163 billion respectively. Typhoon loss has a mean of 0.0102 billion and a standard deviation of 0.0437 . Flood loss has a mean of 0.0022 billion and a standard deviation of 0.0094 . We can find that typhoon and flood variables exhibit the characteristic features of loss time series like excess kurtosis and positive skewness (right tail). The normality hypothesis is rejected for all cases, at every confidence level, according to the Jarque Bera test and robust skewness and kurtosis measured that is significant when higher than 3. It means that the empirical observations of returns display fatter tails than the normal distribution.

\section{B. The results}

Table 1 presents the TVaR and economic capital (EC) under climate change dependences of the crop loss due to typhoons and floods are calculated in the Taiwan in 19712012. It is effective to best fitted the series using $A R(1)$ $\operatorname{GJR}(1,1)$ - GARCH$(1,1)$ model which the minimum values of AIC or BIC and maximum values of LL in all models. We can thus observe that the different models can capture different results of value of TVaR and economic capital on crop loss due to 9 cases of large typhoon and 6 cases of lager flood losses. In this case, we see that the Herb typhoon and June flood need to be protected by the catastrophe (Cat) insurance. The findings will be important in providing useful knowledge to future help examining risk measures that measure TVaR loss that can be used for determining 
Proc. of the Seventh International Conference On Advances in Economics, Management and Social Study - EMS 2017. Copyright (C) Institute of Research Engineers and Doctors. All rights reserved.

ISBN: 978-1-63248-128-3 doi: 10.15224/ 978-1-63248-128-3-39

provisions and capital requirements in order to avoid insolvency on government agricultural budgeting or insurer's coverage and to discovering effective regulations of crop insurance design and to enhance the efficiency of agricultural markets.

TABLE I. TVAR AND ECONOMIC CAPITAL (EC) UNDER CLIMATE CHANGE DEPENDENCE IN TAIWAN

\begin{tabular}{|c|c|c|c|c|c|c|}
\hline & & & \multicolumn{4}{|c|}{ Copula } \\
\hline \multicolumn{7}{|l|}{ Typhoon } \\
\hline $\begin{array}{l}\text { Typhoon } \\
\text { name }\end{array}$ & year & moth & $\begin{array}{c}\text { Loss } \\
\text { amount }\end{array}$ & $\begin{array}{c}\text { Tail } \\
\text { VaR } \\
\text { (TVaR) }\end{array}$ & $\begin{array}{l}\text { Economic } \\
\text { capital(EC) }\end{array}$ & $\begin{array}{c}\text { Should } \\
\text { government } \\
\text { provide Cat } \\
\text { insurance } \\
\text { for crops? }\end{array}$ \\
\hline Herb & 1996 & 8 & 0.5343 & \multirow[t]{9}{*}{0.5202} & \multirow[t]{9}{*}{0.5100} & Must \\
\hline Morakot & 2009 & 8 & 0.3074 & & & May be \\
\hline Korsa & 2007 & 10 & 0.2328 & & & May be \\
\hline Haitang & 2005 & 7 & 0.2092 & & & May be \\
\hline Fanapi & 2010 & 9 & 0.2059 & & & May be \\
\hline Zeb & 1998 & 10 & 0.1868 & & & May be \\
\hline Jangmi & 2008 & 9 & 0.1980 & & & May be \\
\hline Bilis & 2000 & 8 & 0.1840 & & & May be \\
\hline Midulle & 2004 & 6 & 0.1019 & & & May be \\
\hline \multicolumn{7}{|l|}{ Flood } \\
\hline $\begin{array}{c}\text { Flood } \\
\text { name }\end{array}$ & 2005 & 6 & 0.1163 & \multirow[t]{6}{*}{0.1149} & \multirow[t]{6}{*}{0.1127} & Must \\
\hline $\begin{array}{l}\text { June } \\
\text { Flood }\end{array}$ & 2011 & 11 & 0.0783 & & & May be \\
\hline $\begin{array}{c}\text { Apr. } \\
\text { Flood }\end{array}$ & 2012 & 4 & 0.0781 & & & May be \\
\hline $\begin{array}{c}\text { May } \\
\text { Flood }\end{array}$ & 2006 & 5 & 0.0694 & & & May be \\
\hline $\begin{array}{c}\text { June } \\
\text { Flood }\end{array}$ & 1998 & 6 & 0.0547 & & & May be \\
\hline $\begin{array}{c}\text { June } \\
\text { Flood }\end{array}$ & 1997 & 6 & 0.0375 & & & May be \\
\hline
\end{tabular}

\section{Discussion}

This paper used mean AR(1)-GJR-GARCH(1,1) model and out-of-sample large loss cases reruns to test the accuracy of the expected loss, TVaR and economic capital (EC) estimates. It will show an alternative way to model joint distribution of random variables with greater flexibility both in terms of marginal distributions and the dependence structure. Herein, this research will present an application of these models to the coverage of crop insurance contracts for all counties/cities on coverage of the large losses by insured associated with the current agricultural programs. This research provide a summary and implications of the models for weather systemic risk in Taiwan's crop insurance program and results for the viability of private crop insurance contracts and concomitant arguments for government support through subsidized premiums and reinsurance argument program in future.

\section{References}

[1] Antonio K, Beirlant, J (2007), Actuarial statistics with generalized linear mixed models. Insurance: Mathematics and Economic, 40:5876.

[2] Babcock, B. A., Hart, C. E. and Hayes, D. J. (2004), Actuarial fairness of crop insurance rates with constant rate relativities, American. Journal of Agricultural Economics, 86(3):563-575.
[3] Barry, B. and Skees, J. (1994), An empirical analysis of the demand for multiple peril crop insurance: Comment, American. Journal of Agricultural Economics, 76, 948-951.

[4] Boland, Philip J. (2007), Statistical and probabilistic methods in actuarial science, Chapman \& Hall/CRC, New York.

[5] Bowers, N.L., Gerber, H., Hickman, J., Jones, D. and Nesbitt, C (1997), Actuarial mathematics, 2nd ed., Itasca, Illinois, the Society of Actuaries.

[6] Calem, P.S. and LaCour-Little, M. (2001), Risk-based capital requirements for mortgage loans, Board of Governors of the Federal Reserve, Finance and Economics Discussion Series 2001-060.

[7] Calem, P. S. and LaCour-Little, M. (2004), Risk-based capital requirements for mortgage loans, Journal of Banking and Finance, 28: 647-672.

[8] Carriquiry, M.A., Babcock, B.A. and Hart. C.E. (2008), Using a farmer' $\mathrm{s}$ beta for improved estimation of expected yields, Journal of Agricultural and Resource Economics 33:52-68.

[9] Chang, C.C. (2002), The potential impact of climate change on Taiwan's agriculture. Agricultural Economics, 27:51-64.

[10] Chang, C.C., Chen, C. C. and McCarl, B. (2012), Evaluating the economic impacts of crop yield change and sea level rise induced by climate change on Taiwan's agricultural sector., Agricultural Economics, 43:205-214.

[11] Chen, C. C. and Chang, C.C., (2005), The impact of weather on crop yield distribution in Taiwan: some new evidence from panel data models and implications for crop insurance, Agricultural Economics, 33:503-511.

[12] Chatrath A, Adrangi B, Dhanda K.K. (2002), Are commodity prices chaotic? Agricultural Economics, 27:123-137.

[13] Cooper, J., Langemeier M., Schnitkey G. and Zulauf C. (2009), Constructing farm level yield densities from aggregated data: analysis and comparison of approaches, paper presented at the Agricultural and Applied Economics Association Annual Meeting, 26-28 July, Milwaukee, WI.

[14] Glauber, J. W. (2004), Crop insurance reconsidered, American Journal of Agricultural Economics, 86(5):1179-1195.

[15] Goodwin, B. K. (1993), An empirical analysis of the demand for multiple peril crop insurance, American. Journal of Agricultural Economics, 75, 425-434.

[16] Goodwin, B. K. (1994), An empirical analysis of the demand for multiple peril crop insurance: Reply, American. Journal of Agricultural Economics, 76, 952-953.

[17] Goovaerts, M., DeVijlder, F. and Haezendonck, J. (1984), Insurance premiums, Amsterdam: North Holland Publishers.

[18] Kaas, R., Goovaerts, M., Dhaene, J. and Denuit, M. (2001), Modern actuarial risk theory, Netherlands: Kluwer Academic Publishers.

[19] Kalisch,A., Zemek, O. and Schellhardt, S. (2011), Adaptation in agriculture in Porsché,I., Kalisch, A. \& Füglein,R. (eds.) Adaptation to climate change aith a focus on rural areas and India, Deutsche Gesellschaft für Internationale Zusammenarbeit (GIZ), New Delhi.

[20] Lai, Li-Hua (2010), Risk estimate of rice damaged due to flood, Nonlinear Analysis: Real World Applications. 11:1243-1248.

[21] Lai, Li-Hua (2015), Statistical premium in correlated losses of insurance, Economic Modelling, 49:248-253.

[22] Lai, Li-Hua (2017), Economic capital, loss models and climate change dependence: The case of single-peril and combined-peril in crop insurance program, Project Plan, Ministry of Science and Technology, Taiwan, MOST 105-2410-H-327-008, August 2016 July 2017.

[23] Lai, Li-Hua and Wu, Pei-Hsuan (2013), Tail-related risk measures of extreme value distribution: The case of Taiwan' s rice damage due to typhoons in the non-crops insurance plan, Variance:Advancing the Science of Risk, 7(2):152-167.

[24] Luo Y, Teng P.S., Fabellar N.G., TeBeest D.O. (1998): Risk analysis of yield losses caused by rice leaf blast associated with temperature changes above and below for five Asian countries, Agricultural Ecosystems Environment, 68:197-205.

[25] Rejesus, R.M., Goodwin, B.K., Coble, K.H. and. Knight, T.O., (2010), Evaluation of the reference yield calculation method in crop insurance, Agricultural Finance Review 70(3):427-445.

[26] Rudstrom, M., Popp, M., Manning, P. and Gbur, E. (2002), Data aggregation issues for crop yield risk analysis, Canadian Journal of Agricultural Economics, 50(2), 185-200. 
Proc. of the Seventh International Conference On Advances in Economics, Management and Social Study - EMS 2017. Copyright (C) Institute of Research Engineers and Doctors. All rights reserved.

ISBN: 978-1-63248-128-3 doi: 10.15224/ 978-1-63248-128-3-39

[27] Schmock, U. and Straumann, D. (1999), Allocation of risk capital and performance measurement, Talk at the Conference on Quantitative Methods in Finance, Sydney, Australia.

[28] Skees, J. and Reed, M. (1986), Rate Making for Farm-Level Crop Insurance: Implications for Adverse Selection, American. Journal of Agricultural Economics, 68(3):653-659.

[29] Woodard, J. D., Sherrick, B. J. and Schnitke, G. D., (2011), Actuarial impacts of loss cost ratio ratemaking in U.S. crop insurance program, Journal of Agricultural and Resource Economics 36(1):211-228.

[30] Yun, J.I. (2003), Predicting regional rice production in South Korea using region data and crop-growth modeling, Agricultural Systems, 77:23-38.Trans. Roy. Soc. London, vol. A247, pp. 529-551, April 1955 .

About Author (s):

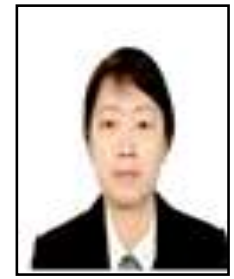

Lihua Lai, is a professor in the Department of Risk Management and Insurance at National Kaohsiung First University of Science and Technology, Taiwan. She has published articles in journals such as Geneva Risk and Insurance Review, Nonlinear Analysis Series B: Real World Applications, Transportation Research Part A: Policy and Practice. Prof. Dr. Lai is a chairman, Southern Region Branch, Risk Management Society of Taiwan. Her research activities include enterprise risk management, property and casualty insurance, actuarial mathematics, insurance financial and economic and agricultural risk assessment.

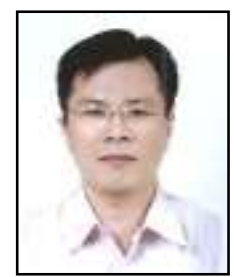

Tung-Cheng Chang now is a Ph.D candidate of Risk Management and Insurance in National Kaohsiung First University of Science and Technology, Taiwan. His specialization is in the risk management of property and casualty insurance.

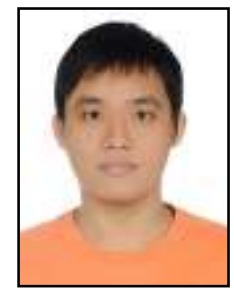

Wong Kai Wen, obtained his master degree of Risk Management and Insurance from National Kaohsiung First University of Science and Technology, Taiwan in 2017. He is interested in financial quantitative analysis and modeling.

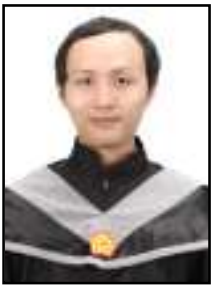

Ching-Hsuan Dai, obtained his master degree of Risk Management and Insurance from National Kaohsiung First University of Science and Technology, Taiwan in 2016. He is an expert in life insurance, personal financial planning and risk management. 